\title{
Contrast Spreading Patterns in Retrodiscal Transforaminal Epidural Steroid Injection
}

\author{
Chul Kim, M.D., Ph.D., Hee Eun Choi, M.D., Seonghoon Kang, M.D.
}

\author{
Department of Physical Medicine and Rehabilitation, Sanggye Paik Hospital, Seoul 139-707, Korea
}

\begin{abstract}
Objective To observe the contrast spreading patterns in the retrodiscal (RD) approach for transforaminal epidural steroid injections and their effect on pain reduction.

Method Patients with L5 radiculopathy who were scheduled to receive lumbar TF-EPB were consecutively included. We randomly divided them into the L4-5 RD and L5-S1 RD groups and administered 1 cc of contrast dye into epidural space. We observed the shape and the location of contrast dye on the anterior-posterior and lateral views. We injected $1 \mathrm{cc}$ of $0.5 \%$ lidocaine mixed with $20 \mathrm{mg}$ of triamcinolone, and checked the pain intensity before and two weeks after the procedure by using visual analogue scale (VAS).

Results In the L4-5 RD group ( $\mathrm{n}=30$ ), contrast spread over the L4 nerve root in 27 cases and the L4 and L5 nerve roots in 3 cases. In the L5-S1 RD group ( $\mathrm{n}=33$ ), contrast spread over the L5 nerve root in 20 cases, the S1 nerve root in 3 cases, and the L5 and the S1 nerve roots in 10 cases. The contrast spreading patterns could be divided into 4 patterns: the proximal root in 40 cases, the distal root in 19 cases, the anterior epidural space in 3 cases and an undefined pattern in 1 case.

Conclusion In RD lumbar TF-EPB, the contrast dye mostly went into the cephalic root and about $60 \%$ spread over the proximal nerve root. There was less pain reduction when the contrast dye spread over the distal nerve root.
\end{abstract}

Key Words Contrast dye, Epidural block, Retrodiscal, Transforaminal

\section{INTRODUCTION}

Epidural steroid injection has been used for treating pain due to lumbosacral radiculopathy. ${ }^{1}$ The injections can be delivered into interlaminar, caudal, and transfo-

Received December 16, 2011; Accepted June 25, 2012

Corresponding author: Seonghoon Kang

Department of Physical Medicine and Rehabilitation, Sanggye Paik Hospital, 761-1, Sanggye 7 dong, Nowon-gu, Seoul 139-707, Korea

Tel : +82-2-950-1390, Fax : +82-2-935-3076, E-mail: shgang777@hanmail. net, ckim@paik.ac.kr

(C) This is an open-access article distributed under the terms of the Creative Commons Attribution Non-Commercial License (http:// creativecommons.org/licenses/by-nc/3.0) which permits unrestricted noncommercial use, distribution, and reproduction in any medium, provided the original work is properly cited.

Copyright $\odot 2012$ by Korean Academy of Rehabilitation Medicine raminal locations. Because of its advantage of selectively injecting drugs into a specific nerve root, transforaminal injection method is preferred. ${ }^{1,2}$ There are 3-4 types of well-known approaches in the transforaminal injection method, and among those, the most used is the infrapedicle transforaminal injection which has the injection needle approach the safe triangle below the underside of the pedicle so that contrast dye usually spreads to $\mathrm{L} 4$ root in case of L4-5 level, and if the L5-S1 level, mostly spreads to L5 root. ${ }^{3}$ Preganglionic approach accesses the suprapedicle level, and contrast dye is known to spread over to L5 root in case of L4-5 level, and to S1 root in case of L5S1 level. ${ }^{4}$

In the case of infrapedicle approach, there are numer- 
ous cases where the injected drug would flow into the cephalic root of the nerve root, and in the case of severe foraminal stenosis, in many cases the injection needle is unable to reach the desired location after penetrating the intervertebral foramen. ${ }^{5}$ Furthermore, with regard to infrapedicle approach, there are even cases where drugs cannot be injected into the epidural and preganglionic part of the supraadjacent intervertebral disc. ${ }^{4}$ At that point, a retrodiscal (RD) approach can be used as an alternative method.

In determining the level of retrodiscal (RD) approach, it is critical to know to which nearby nerve root the contrast dye spreads. Current research is not clear on spread patterns of RD EPB contrast dye.

In this study, the authors investigated the spreading pattern and location of contrast dye and the clinical features of the transforaminal epidural block according to the retrodiscal $(\mathrm{RD})$ approach, relatively unknown to the present.

\section{MATERIALS AND METHODS}

\section{Subjects}

The patients, who visited the Department of Rehabilitation at the authors' hospital with chief complaints of back pain and radiating pain, were diagnosed as L5 radiculopathy by physical examination, medical imaging, and electromyographic examination. Patients who were planning to receive transforaminal injection treatment were consecutively included.

Patients who had received steroid injections or prescriptions within the previous three months, or had a history of diabetes, general peripheral neuropathy, cerebrovascular accident, or inflammatory joint disease were excluded from the study. To examine which nerve root the drug injection spreads to, the subject patients were consecutively randomized into L4-5 RD approach group and L5-S1 RD approach group.

\section{Methods}

The subjects lay prone on the C-arm table with a pillow supporting the lower abdomen and upper iliac to reduce lumbar lordosis, and the C-arm was tilted from the cranial to caudal part in order to align the superior-inferior ephiphyseal plate of the relevant vertebrae. Then, the Carm was rotated at a 40-45 degree angle to the limbs, and the superior articular process of $\mathrm{S} 1$ was set to be placed in the central point of the disc space. 22 gauge 5 inch spinal needle; Spinal needle Spinocan ${ }^{\circledR}$ (BRAUN, Melsungen, Germany) was inserted into the skin and was pressed forward to the side that is parallel to the axis of the X-ray route. Once the spinal needle passes through the extrapolation of the superior articular process and comes in contact with the retrodiscal (RD) surface, the needle is checked to see that it did not go over the virtual disc back line by turning the $\mathrm{C}$-arm towards the lateral view.

To examine the spreading pattern of the contrast dye, 1 cc of non-ionic contrast dye; Omnipaque ${ }^{\mathrm{TM}}$ (GE Healthcare, Cork, Ireland) was injected, and through the anterior-posterior and lateral views of the X-ray, the spreading pattern of the contrast dye and the nerve root it usually spreads to were observed. In addition, for the treatment, $1 \mathrm{cc}$ of $0.5 \%$ lidocaine mixed with $20 \mathrm{mg}$ of triamcinolone was injected.

To examine if there is an association between the spreading pattern of contrast dye and pain reduction, a visual analogue scale (VAS) was obtained before and 2 weeks after the procedure.

\section{RESULTS}

\section{General characteristics of subject patients}

There was 30 people (Men: 9, Women: 21) in the L4-5 $\mathrm{RD}$ group, and 33 people in the L5-S1 RD group (Men: 12, Women: 21 ). The average age of L4-5 RD group was $61.10 \pm 12.94$ years, and that of L5-S1 RD group was $59.67 \pm 11.34$ years. In the $\mathrm{L} 4-5 \mathrm{RD}$ group, 16 people had the pain on the right side and 14 had the pain on the left,

Table 1. Patient Characteristics

\begin{tabular}{|c|c|c|c|}
\hline & L4-L5 RD* & L5-S1 RD & Total \\
\hline $\begin{array}{l}\text { Number of } \\
\text { subjects }\end{array}$ & 30 & 33 & 63 \\
\hline Male/Female & $9 / 21$ & $12 / 21$ & $21 / 42$ \\
\hline Age (years) & $61.10 \pm 12.94$ & $59.67 \pm 11.34$ & $60.35 \pm 12.05$ \\
\hline Rain side (Rt/Lt) & $16 / 14$ & $27 / 6$ & $43 / 20$ \\
\hline Initial VAS $^{\dagger}$ & $5.77 \pm 1.31$ & $6.12 \pm 1.21$ & $5.95 \pm 1.26$ \\
\hline $\begin{array}{l}\text { CT findings } \\
\left(\mathrm{HIVD}^{\ddagger} / \mathrm{SS}^{\S}\right)\end{array}$ & $20 / 10$ & $19 / 11$ & $39 / 21$ \\
\hline
\end{tabular}

${ }^{*}$ RD: Retrodiscal, ${ }^{\dagger}$ VAS: Visual analogue scale, ${ }^{\ddagger}$ HIVD: Herniated intervertebral disc, ${ }^{8}$ SS: Spinal stenosis 
in the L5-S1 RD group, 27 people on the right side, and 6 on the left side. The visual analogue scale (VAS) was $5.77 \pm 1.31$ in the L4-5 RD group, and 6.12 \pm 1.21 in the L5S1 RD group. CT revealed L5-S1 herniated intervertebral disc in 20 people, spinal stenosis in 10 in the L4-5 RD group. In the L5-S1 RD group, 19 had L5-S1 herniated intervertebral disc and 11 had spinal stenosis. There was no significant difference between the two groups in general characteristics (Table 1).

Nerve root spreading location of contrast dye according to procedure level

Contrast dye usually spread over to the upper nerve root. In the L4-5 RD group, the contrast spread over the L4 nerve root in 27 cases, and the L4 and L5 nerve roots in 3 cases. Out of the 33 subjects in the L5-S1 RD group, the contrast spread to the L5 nerve root in 20 cases, to both the L5 and S1 nerve root in 10 cases, and to the S1 nerve root in 3 cases (Table 2).

\section{Contrast spreading pattern}

The contrast spreading pattern could be divided into

Table 2. Contrast Dye Spreading Locations

\begin{tabular}{lcc}
\hline & L4-L5 RD* & L5-S1 RD \\
\hline L4 root & 27 & 0 \\
L5 root & 0 & 20 \\
S1 root & 0 & 3 \\
Both L4 \& L5 roots & 3 & 0 \\
Both L5 \& S1 roots & 0 & 10 \\
Total & 30 & 33 \\
\hline
\end{tabular}

*RD: Retrodiscal four patterns (Fig. 1 4): 40 cases where the contrast dye usually spread to the distal target nerve root, 19 cases where the contrast dye usually spreads to the proximal target nerve root, 3 cases where the contrast spreads to the anterior epidural space, and lastly, 1 case with an undefined pattern which does not fall under any of the previous three patterns (Table 3).

\section{Contrast spreading pattern and clinical characteristics due to it}

The pain intensity 2 weeks after the procedure (VAS) was $2.750 \pm 0.670$ in the group where contrast spread to the proximal nerve root, and $3.210 \pm 0.630$ in the group where it spread to the distal nerve root, a statistically significant difference. The changes in pain after the procedure (VAS change) also were statistically significant, comparing $3.925 \pm 0.829$ in the group where the contrast spread to the proximal nerve root, and $3.421 \pm 0.697$ in the group where it spread to the distal root (Table 4).

\section{DISCUSSION}

Table 3. Contrast Dye Spreading Patterns

\begin{tabular}{lccc}
\hline & L4-L5 RD & L5-S1 RD & Total \\
\hline Proximal $^{*}$ & 18 & 22 & 40 \\
Distal $^{\dagger}$ & 9 & 10 & 19 \\
Anterior $^{\dagger}$ & 2 & 1 & 3 \\
Undefined $^{\S}$ & 1 & 0 & 1 \\
Total & 30 & 33 & 63 \\
\hline
\end{tabular}

*Spread to proximal root, ${ }^{\dagger}$ Spread to distal root, ${ }^{*}$ Spread to Anterior epidural space, ${ }^{S}$ Undefined pattern
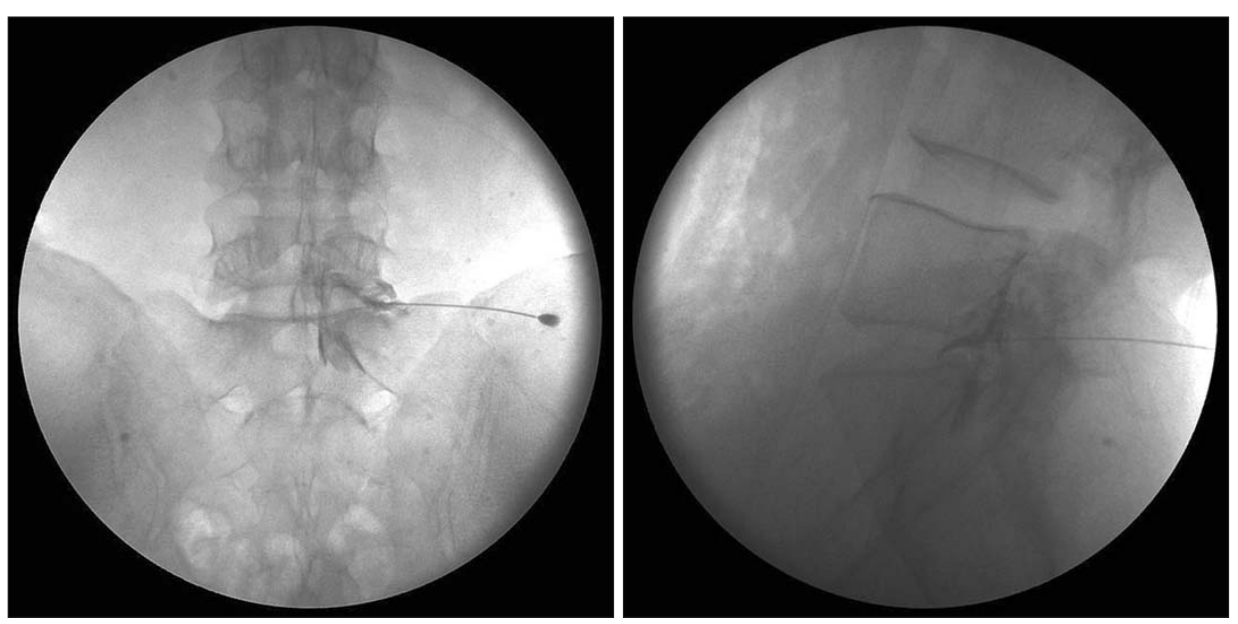

Fig. 1. Contrast spread to proximal nerve root. 
Transforaminal epidural injection method has an excellent curative effect in treating chronic lumbar nerve root pain syndrome, and has been used extensively in a clinical setting due to its satisfactory effect in the long term. ${ }^{6}$

When transforaminal epidural injection method is performed, the contrast dye must spread over to the proximal region along the anterior lateral part of a specific nerve ${ }^{7,8,9}$ However, a considerable amount of the drug injected via infrapedicle approach sometimes flows into

Table 4. Comparison of VAS* between Proximal and Distal Group

\begin{tabular}{lccc}
\hline & $\begin{array}{c}\text { Proximal group } \\
(\mathbf{n}=\mathbf{4 0})\end{array}$ & $\begin{array}{c}\text { Distal group } \\
(\mathbf{n}=\mathbf{1 9})\end{array}$ & p-value \\
\hline Initial VAS & $6.675 \pm 0.474$ & $6.684 \pm 0.478$ & 0.944 \\
Final VAS & $2.750 \pm 0.670$ & $3.210 \pm 0.630$ & $0.016^{\dagger}$ \\
VAS change & $3.925 \pm 0.829$ & $3.421 \pm 0.697$ & $0.049^{\dagger}$ \\
\hline
\end{tabular}

*VAS: Visual analogue scale, ${ }^{\dagger} \mathrm{p}<0.05$ the distal region along the spinal nerve, and it becomes difficult to insert the injection needle in the case of severe spinal stenosis when the needle is supposed to be located at the region more anterior to the intra-transforaminal epidural nerve root. ${ }^{10}$

As an alternative to this, the retrodiscal (RD) approach can be applied. The researchers have concluded that the epidural block by L5-S1 retrodiscal (RD) approach can reduce the stimulation to the nerve root during the procedure compared to the infrapedicle approach. This is a helpful method especially when the disc sequestrum is stuck in the medial intervertebral foramen or when spinal stenosis is severe. ${ }^{10}$

With regard to determining the level of RD approach, it is very important to be aware of which nearby nerve roots the contrast dye is spreading to. However, studies done on which nerve root the drugs spread to are insufficient. The authors found that the contrast dye mainly spreads over the upper nerve root regardless of the level of the
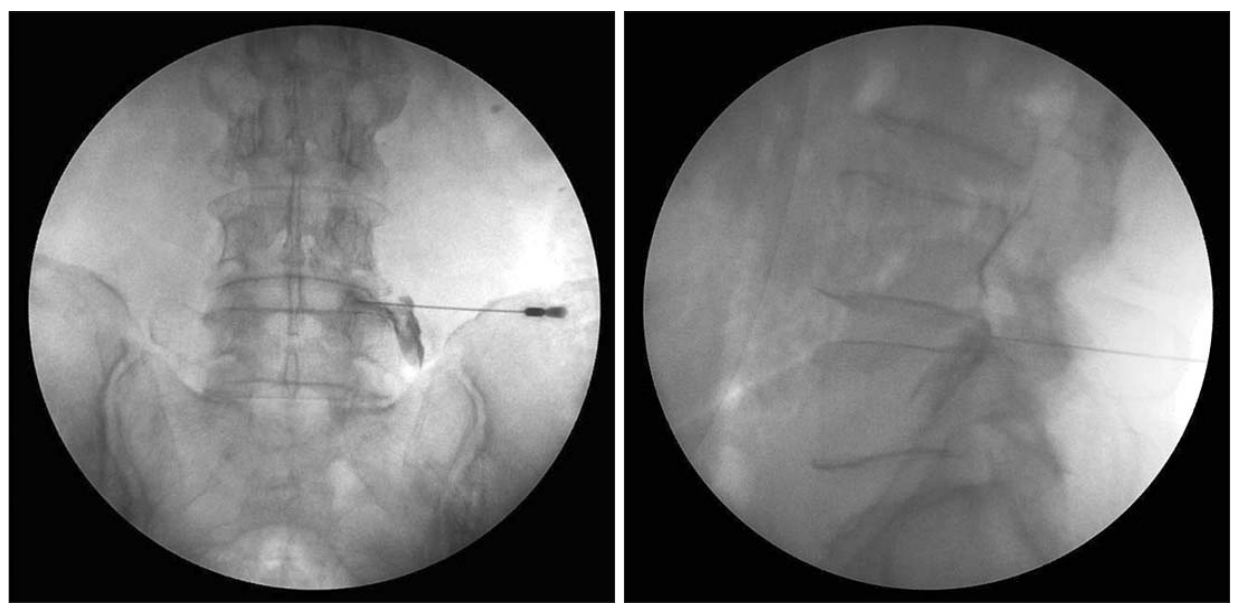

Fig. 2. Contrast spread to distal nerve root.
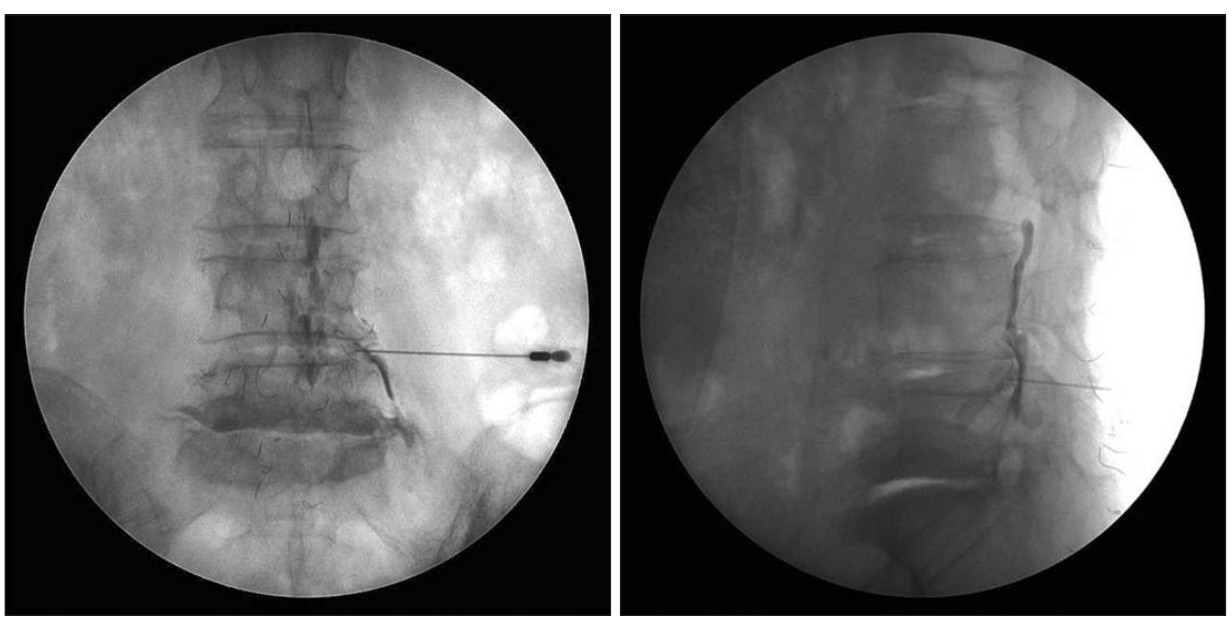

Fig. 3. Contrast spread to anterior epidural space. 

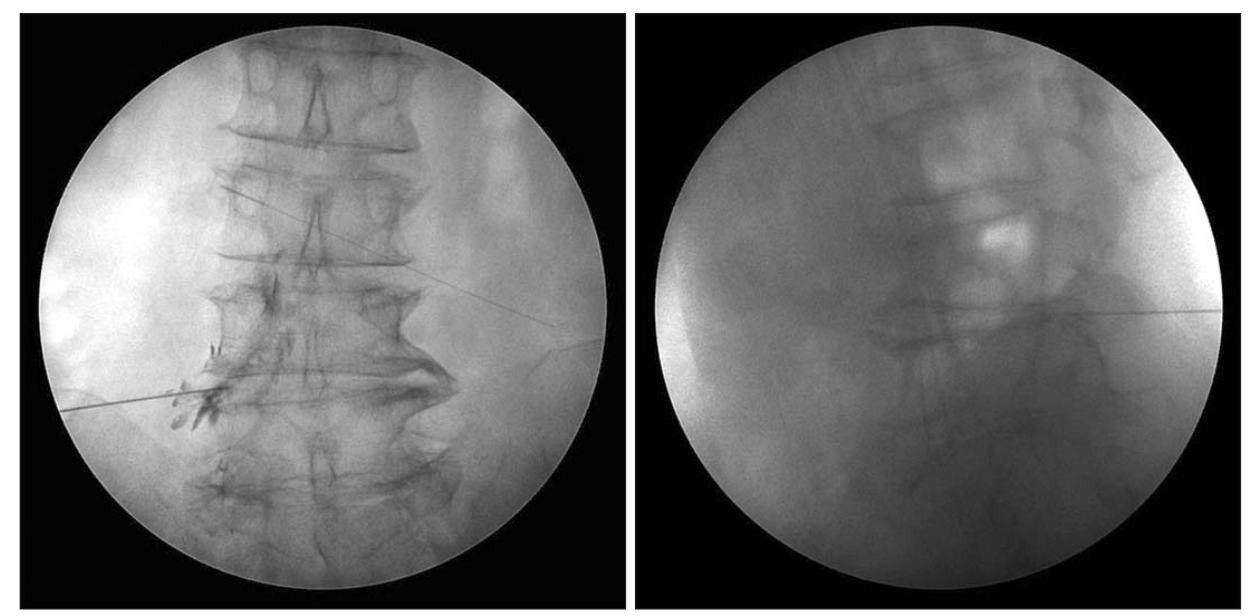

Fig. 4. Contrast spread to undefined pattern.

procedure when performing a procedure with the $\mathrm{RD}$ approach (Table 2). This is likely due to the anatomical structure of the spinal epidural space. Although contralateral spread of the contrast dye was not observed in this study, the authors noted that in a considerable number of cases, the contrast spread to even the nerve roots below the level of the targeted nerve root apart from the targeted nerve root. When over $0.5 \mathrm{ml}$ of contrast dye was injected, the contrast can spread to more than one of the nearby (superior, inferior, and/or contralateral) nerve roots. ${ }^{7,11}$ Because $1.0 \mathrm{ml}$ of contrast dye was administered in this study, it was observed that the contrast spread to not only the targeted nerve roots but also to the nerve roots below the level of the targeted nerve roots.

The authors found that the contrast dye in the RD approach usually spread to the proximal target nerve root $(40 / 63,63.5 \%)$ (Table 3$)$. In case of the contrast dye spreading to the distal root, the authors observed that the resulting changes in pain (VAS change) before and after procedure was less compared to the patients with a spread to the proximal root. This is attributed to the inability of the contrast dye to rise to the proximal nerve root and its flowing down to the distal root following the spinal nerve by the synechia of epidural space including the root sleeve.

This study has its limitations. First, when recruiting the subject group for this study, all patients with severe spinal stenosis or herniated intervertebral disc were included, and because some patients with severe synechia of epidural space were included among them, there were many cases where the injected drugs spread to the distal nerve root. Therefore, if a study is conducted in the future to judge the effect of the contrast spreading pattern on pain reduction, it should be carried out after excluding patients with severe spinal stenosis or severe herniated intervertebral disc. Second, the level of pain was recorded with VAS before the procedure and two weeks after the procedure. It seems that using another scale besides VAS would be helpful to enhance the objectivity of the results. Furthermore, the mid- to long-term effect of the procedures could be identified if follow-up is conducted not only two weeks but also six months or more after the procedure.

\section{CONCLUSION}

When performing lumbosacral transforaminal epidural block by the retrodiscal (RD) approach, the contrast dye mostly spread to the cephalic root regardless of the level of the procedure. The pain-reducing effect two weeks after the procedure was better when the contrast dye spread over to the relevant proximal nerve root rather than to the distal root.

\section{ACKNOWLEDGEMENTS}

This work was supported by the 2011 Inje University research grant.

\section{REFERENCES}

1. Botwin KP, Gruber RD, Bouchlas CG, Torres-Ramos FM, Sanelli JT, Freeman ED, Slaten WK, Rao S. Fluoroscopically guided lumbar transforaminal epidural steroid injections in degenerative lumbar stenosis: an outcome study. Am J Phys Med Rehabil 2002; 81: 898- 
905

2. Slipman CW, Chow DW. Therapeutic spinal corticosteroid injections for the management of radiculopathies. Phys Med Rehabil Clin N Am 2002; 13: 697-711

3. Derby R, Bogduk N, Kine G. Precision percutaneous blocking procedures for localizing spinal pain: part 2. The lumbar neuroaxial compartment. Pain Digest 1993; 3: 175-188

4. Lew HL, Coelho P, Chou LH. Preganglionic approach to transforaminal epidural steroid injections. Am J Phys Med Rehabil 2004; 83: 378

5. Lee IS, Kim SH, Lee JW, Hong SH, Choi JY, Kang HS, Song JW, Kwon AK. Comparison of the temporary diagnostic relief of transforaminal epidural steroid injection approaches: conventional versus posterolateral technique. AJNR Am J Neuroradiol 2007; 28: 204208

6. Jasper JF. Lumbar retrodiscal transforaminal injection. Pain Physician 2007; 10: 501-510
7. Smuck M, Fuller BJ, Yoder B, Huerta J. Incidence of simultaneous epidural and vascular injection during lumbosacral transforaminal epidural injections. Spine J 2007; 7: 79-82

8. Derby R, Lee SH, Kim BJ, Chen Y, Seo KS. Complications following cervical epidural steroid injections by expert interventionalists in 2003. Pain Physician 2004; 7: $445-449$

9. Alleyne CH Jr, Cawley CM, Shengelaia GG, Barrow DL. Microsurgical anatomy of the artery of Adamkiewicz and its segmental artery. J Neurosurg 1998; 89: 791795

10. Kim C, Moon CJ, Choi HE, Park YB. Retrodiscal approach of lumbar epidural block. Ann Rehabil Med 2011; 35: 418-426

11. Furman MB, Lee TS, Mehta A, Simon JI, Cano WG. Contrast flow selectivity during transforaminal lumbosacral epidural steroid injections. Pain physician 2008; 11: 855-861 